\title{
The uptake of phosphorus acid sprays into kauri foliage
}

\author{
D.B. Horgan
}

Plant Protection Chemistry NZ, PO Box 6282, Rotorua 3043, New Zealand

Corresponding author: david.horgan@ppcnz.co.nz

Kauri dieback caused by Phytophthora agathidicida is a serious problem affecting forests throughout the upper North Island. A potential control tool is the use of phosphorus acid (phosphite) as a foliar spray. This study investigates various commercial formulations of phosphorus acid in combination with adjuvants, for their potential uptake into kauri foliage. Large differences were seen in the uptake between the upper (adaxial) and lower (abaxial) leaf surfaces. The upper kauri leaf surface gave negligible uptake $(<5 \%)$ while the lower surface had $>65 \%$ uptake across all formulations tested. From these results, the potential for spray operations is discussed.

\section{Ploidy in Lolium spp. cultivars affects Argentine stem weevil parasitism by Microctonus hyperodae}

\author{
F. Tomasetto ${ }^{1}$, O. Olaniyan ${ }^{2,3}$ and S.L. Goldson ${ }^{1,4}$ \\ ${ }^{1}$ AgResearch Ltd, Private Bag 4749, Christchurch 8140, New Zealand \\ ${ }^{2}$ Lincoln University, PO Box 85084, Lincoln 7647, New Zealand \\ ${ }^{3}$ University of Jos, Nigeria, P. M. B. 2084, Jos, Plateau State, Nigeria \\ ${ }^{4}$ Bio-Protection Research Centre, PO Box 85084, Lincoln University, Lincoln 7647, New Zealand \\ Corresponding author: federico.tomasetto@agresearch.co.nz
}

A laboratory study was conducted to: (1) advance earlier work to determine the susceptibility of Listronotus bonariensis (Argentine stem weevil) to its parasitoid biological control agent, Microctonus hyperodae, in the presence of diploid ryegrasses such as Lolium multiflorum or Lolium perenne; and (2) determine whether or not plant orientation (i.e. horizontal vs. vertical) had any effect on parasitism rates. No significant differences in parasitism rates were found in the Listronotus bonariensis populations in the two grasses. However, combining and analysing these data with those from an earlier experiment conducted in the same way showed that parasitism rates were significantly lower in diploid Lolium multiflorum cultivars than in tetraploid Lolium multiflorum. This is the first clear evidence of a ploidy effect on parasitism rates in the presence of Lolium multiflorum. Tetraploid Lolium multiflorum has fewer, more robust and larger tillers than the diploid Lolium spp. so higher parasitism rates may be related to the lack of hiding places for an evasive genetically-driven behaviourally-based resistance by Listronotus bonariensis. 